\title{
Silencing of the phytoene desaturase (PDS) gene affects the expression of fruit-ripening genes in tomatoes
}

\author{
Aung Htay Naing ${ }^{1 \dagger}$, Swum Yi Kyu ${ }^{1 \dagger}$, Phyo Phyo Win Pe², Kyeung II Park², Je Min Lee ${ }^{1}$, Ki Byung Lim* \\ and Chang Kil Kim ${ }^{1 *}$
}

\begin{abstract}
Background: Past research has shown that virus-induced phytoene desaturase (PDS) gene silencing via agroinjection in the attached and detached fruit of tomato plants results in a pale-yellow fruit phenotype. Although the PDS gene is often used as a marker for gene silencing in tomatoes, little is known about the role of PDS in fruit ripening. In this study, we investigated whether the pepper PDS gene silenced endogenous PDS genes in the fruit of two tomato cultivars, Dotaerang Plus and Legend Summer.

Results: We found that the pepper PDS gene successfully silenced endogenous PDS in tomato fruit at a silencing frequency of $100 \%$ for both cultivars. A pale-yellow silenced area was observed over virtually the entire surface of individual fruit due to the transcriptional reduction in phytoene desaturase (PDS), zeta-carotene (ZDS), prolycopene isomerase (Crt/SO), and beta-carotene hydroxylase (CrtR-b2), which are the carotenoid biosynthesis genes responsible for the red coloration in tomatoes. PDS silencing also affected the expression levels of the fruit-ripening genes Tomato AGAMOUS-LIKE1 (TAGL1), RIPENING INHIBITOR (RIN), pectin esterase gene (PE), lipoxygenase (LOX), FRUITFULL1/FRUITFUL2 (FUL1/FUL2), and the ethylene biosynthesis and response genes 1-aminocyclopropane-1-carboxylate oxidase 1 and 3 ( $A C O 1$ and $A C O 3$ ) and ethylene-responsive genes (E4 and E8).
\end{abstract}

Conclusion: These results suggest that PDS is a positive regulator of ripening in tomato fruit, which must be considered when using it as a marker for virus-induced gene silencing (VIGS) experiments in order to avoid fruit-ripening side effects.

Keywords: Carotenoid biosynthesis, Ethylene biosynthesis, Fruit ripening, Relative gene expression, VIGS

\section{Background}

Virus-induced gene silencing (VIGS) is a widely used reverse genetics tool for the high-throughput analysis of the biological functions of target genes in plants due to its ability to rapidly degrade the mRNA of the target gene, its simplicity in use, and its rapid results. Application of VIGS was first achieved with the silencing of the phytoene desaturase $(P D S)$ gene in tobacco leaves, resulting in visible leaf photo-bleaching [1]. Since then, VIGS has

\footnotetext{
*Correspondence: kblim@knu.ac.kr; ckkim@knu.ac.kr

${ }^{\dagger}$ Aung Htay Naing and Swum Yi Kyu contributed equally to this work ${ }^{1}$ Department of Horticultural Science, Kyungpook National University, Daegu, South Korea

Full list of author information is available at the end of the article
}

been used to investigate the function of genes involved in a number of research areas, including abiotic and biotic defense mechanisms, coloration (i.e., anthocyanin and carotenoid biosynthesis), and plant growth [2-4], and more than 30 plant species have been subject to this form of investigation [5].

With the aim of optimizing the VIGS approach, PDS is widely used as a common marker gene in many plant species due to its ease of detection. The use of VIGS in tomatoes was first achieved by silencing PDS in leaves [6], followed by many more successful PDS-silencing experiments on tomato fruit [7-9]. The increase in carotenoid content (in the order of a 10- to 14-fold increase) during the ripening of tomatoes has been reported [10].

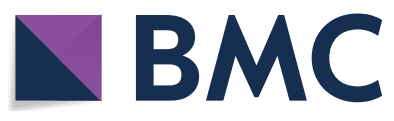

(c) The Author(s) 2019. This article is distributed under the terms of the Creative Commons Attribution 4.0 International License (http://creativecommons.org/licenses/by/4.0/), which permits unrestricted use, distribution, and reproduction in any medium, provided you give appropriate credit to the original author(s) and the source, provide a link to the Creative Commons license, and indicate if changes were made. The Creative Commons Public Domain Dedication waiver (http://creativecommons.org/ publicdomain/zero/1.0/) applies to the data made available in this article, unless otherwise stated. 
The PDS gene encoding the phytoene desaturase enzyme is involved in carotenoid biosynthesis pathway [10] and its silencing in the fruit of tomatoes reduced carotenoid accumulation and led to yellow-colored fruit $[8,9]$. In addition, transcriptional control of PDS in carotenoid biosynthesis in tomato flowers and fruits has also been reported [11-13]. However, the molecular mechanism how the PDS silencing affects carotenoid biosynthesis in tomato fruits has not been well explored. Su et al. [14] reported that carotenoid accumulation during the ripening of tomatoes is controlled by the transcript levels of beta-carotene hydroxylase $(C r t R-b 2)$ gene. In addition, Fantini et al. [13] also claimed that reduction of carotenoid contents in tomato fruits is associated with down-regulation of the carotenoid biosynthesis genes zeta-carotene desaturase $(Z D S)$ and prolycopene isomerase (CrtISO). Hence, we investigated whether PDS silencing influences the regulation of the above mentioned genes involved in carotenoid biosynthesis pathway.

Previously, Kim et al. [15] reported that the silencing of the pepper PDS gene, which has high homology to the PDS gene in tomato and petunia plants, in pepper leaves and fruit led to distinct photo-bleaching. Recently, Naing et al. [16] reported that the pepper PDS gene significantly suppressed endogenous PDS gene in petunia and reduced total chlorophyll content. Hence, pepper $P D S$ was exploited to silence the endogenous $P D S$ gene in tomato fruit. Based on our preliminary work, the silencing of the endogenous PDS gene in detached tomatoes led to fruit with a yellow color that continued until the fruit had softened. Vrebalov et al. [17] observed that the reduction of the RIPENING INHIBITOR (RIN) gene results in the failure of fruit to ripen. In addition, Vrebalov et al. [18] and Itkin et al. [19] also claimed that Tomato AGAMOUS-LIKE1 (TAGL1) is involved in the regulation of fruit ripening and its suppression results in yellow-orange fruits, decreased carotenoids and delayed ripening. Moreover, the involvement of pectin esterase gene (PE), lipoxygenase (LOX), and the two homologous genes FRUITFULL1 (FUL1) and FRUITFUL2 (FUL2) in the ripening of tomatoes has been identified [17, 19-21]. In the present study, we were interested in investigating whether the expression patterns of the fruit-ripening related genes would change in $P D S$-silenced tomato fruits.

Because tomatoes are climacteric fruit, their ripening is associated with the expression of ethylene biosynthesis genes such as 1-aminocyclopropane-1-carboxylate oxidase (ACO) [20, 22-24]. Alexander and Grierson [25] and $\mathrm{Hu}$ et al. [26] reported that the suppression of SlACO1 delayed fruit ripening and ethylene biosynthesis, while the transcript levels of SIACO1 and SIACO3 are markedly high when the ripening of tomatoes is triggered [25,
27]. Similarly, Lincoln et al. [28] and Zhang et al. [20] observed that expression of $E 4$ is positively associated with ethylene biosynthesis, while Kneissl and Deikman [29] also reported that $E 8$ is a fruit ripening-specific gene that is activated during the fruit ripening process, and it is widely used as a fruit-specific promoter in transgenic tomatoes [30, 31].

In summary, in the present study, $P D S$ expression was silenced in the fruit of two commercial tomato cultivars using VIGS to elucidate how PDS silencing affects the fruit phenotype and the expression of the genes mentioned above that are involved in the ripening of tomatoes.

\section{Materials and methods \\ Plant materials}

Seeds of two tomato cultivars, Dotaerang Plus (Takii Korea Co., Ltd.) and Legend Summer (Haesung Seed Plus Co., Ltd.), were sown in plug trays filled with the soil-less mixture BM7 (Berger Co., Quebec, Canada) in a growth chamber at $23{ }^{\circ} \mathrm{C}$, with a $16 \mathrm{~h}$ photoperiod $\left(400 \mu \mathrm{mol} \mathrm{m}^{-2} \mathrm{~s}^{-1}\right)$ and $70 \%$ relative humidity (RH). After 2 weeks, healthy germinated plants of uniform size were transplanted into pots filled with BM7 and moved to a greenhouse at $25-27{ }^{\circ} \mathrm{C}$ (daytime) and $16-18{ }^{\circ} \mathrm{C}$ (night), with a $16-\mathrm{h}$ photoperiod and $70 \% \mathrm{RH}$ for plant growth and fruiting. When the fruit had reached the mature green stage, healthy fruits of uniform size were picked at 8 AM from each cultivar and used for VIGS testing.

\section{Preparation of Agrobacterium suspension}

The use of the tobacco rattle virus (TRV1 and TRV2) in VIGS experiments has been reported for tomatoes [6]. Agrobacterium tumefaciens strain GV3101 harboring the tobacco rattle virus vectors pTRV1, pTRV2 (without $P D S$ ), and pTRV2-PDS was provided by Prof. Je Min Lee (Kyungpook National University, Daegu), while the PDS gene inserted into the vector pTRV2-PDS was cloned from pepper. Bacterial samples each harboring one of the three vectors were separately cultured in LB broth containing $25 \mathrm{mg} \mathrm{L}^{-1}$ kanamycin and rifampicin in a shaking incubator at $300 \mathrm{rpm}$ and $28{ }^{\circ} \mathrm{C}$. When the optical density of the bacteria was $\mathrm{OD}_{600} 0.6$, the cells were centrifuged and the obtained pellets suspended in an inoculation buffer of $10 \mathrm{mM} \mathrm{MgCl}, 10 \mathrm{mM}$ MES (pH 5.6), and $200 \mu \mathrm{M}$ acetosyringone, to obtain a final $\mathrm{OD}_{600}$ of 1.0 for each culture. The cells were then placed in a rotary shaker at $300 \mathrm{rpm}$ and $28^{\circ} \mathrm{C}$ for $6 \mathrm{~h}$.

\section{Agroinjection into detached tomatoes}

Green mature tomatoes were harvested at $8 \mathrm{AM}$ from each cultivar and immediately divided into three groups to be separately injected with a buffer solution alone 
or one of the bacterial suspensions, pTRV1+pTRV2 (TRV1/2) or pTRV1 + pTRV2-PDS (TRV1/2-PDS; Fig. 1). The suspensions were injected through the carpopodium with a 1-mL syringe at room temperature. Once the suspension had infiltrated the tissue, it appeared in the sepals. There were 20 tomatoes per treatment and three replications of each treatment. The injected fruits were placed in a growth chamber at $23^{\circ} \mathrm{C}$, with a 16 -h photoperiod $\left(400 \mu \mathrm{mol} \mathrm{m}^{-2} \mathrm{~s}^{-1}\right)$ and $70 \%$ relative humidity.

\section{Evaluation of fruit phenotype}

Two weeks after injection, the presence of pale yellow and red coloring of the pericarp was evaluated for both cultivars. To determine the silencing frequency, the following calculation was used:

Silencing frequency (\%)

$=$ number of tomatoes with visible silencing/

total number of tomatoes injected $\times 100$

\section{Measurement of gene expression levels using quantitative} real time-PCR

Two weeks after injection, RNA was extracted from the pericarp of the tomatoes injected with the different inoculums; for those injected with TRV1/2-PDS, RNA was extracted from visibly silenced areas. Total RNA extraction was performed using an RNAqueous kit (Ambion Inc., Austin, TX, USA). Reverse transcription was conducted using $1 \mu \mathrm{g}$ of total RNA and an oligo dT20 primer with a ReverTra Ace- $\alpha$ kit (Toyobo Co. Ltd., Osaka, Japan). Transcript levels of the endogenous tomato PDS gene, the carotenoid biosynthesis genes (ZDS, CrtR-b2, and $\mathrm{CrtlSO}$ ), the fruit-ripening-associated genes (FUL1, FUL2, PE, LOX, TAGL1, and RIN), and the ethylene biosynthesis and response genes (ACO1, $A C O 3, E 4$, and $E 8$ ) were measured using a StepOnePlus Real-Time PCR system (Thermo Fisher Scientific Inc., Waltham, MA, USA). Expression levels were normalized to the actin gene to minimize variation in the cDNA template. The primers, accession numbers, and PCR conditions for the examined genes are listed in Additional file 1: Table S1.

\section{Statistical analysis}

For qRT-PCR analysis, total RNA was extracted from three different biological samples, and this analysis was repeated three times for each biological sample. The data were analyzed using SPSS v.11.09 (IBM Corporation, Armonk, NY, USA), and the values of the relative gene expression levels described in the study were means of the three biological replicates. The least significant difference test (LSDT) was used to identify differences between the means. A $P$-value of less than 0.05 was considered statistically significant.

\section{Results}

PDS-silencing fruit phenotype

Mature green tomatoes harvested from the two cultivars (Dotaerang Plus and Legend Summer) were immediately injected with the buffer, TRV1/2, or TRV1/2-PDS. Two weeks after injection, silenced phenotypes associated with PDS were observed in the TRV1/2-PDS tomatoes, but not in those injected with the buffer or TRV1/2. A distinct pale-yellow coloration was observed in fruits of both cultivars injected with TRV1/2-PDS (Fig. 2A, B). In this study, all tomatoes injected with TRV1/2-PDS exhibited a silencing efficiency of $100 \%$, and the silencing patterns of the fruit within the same cultivar were also similar based on visual observations (data not shown). The silenced areas of cv. Legend Summer covered

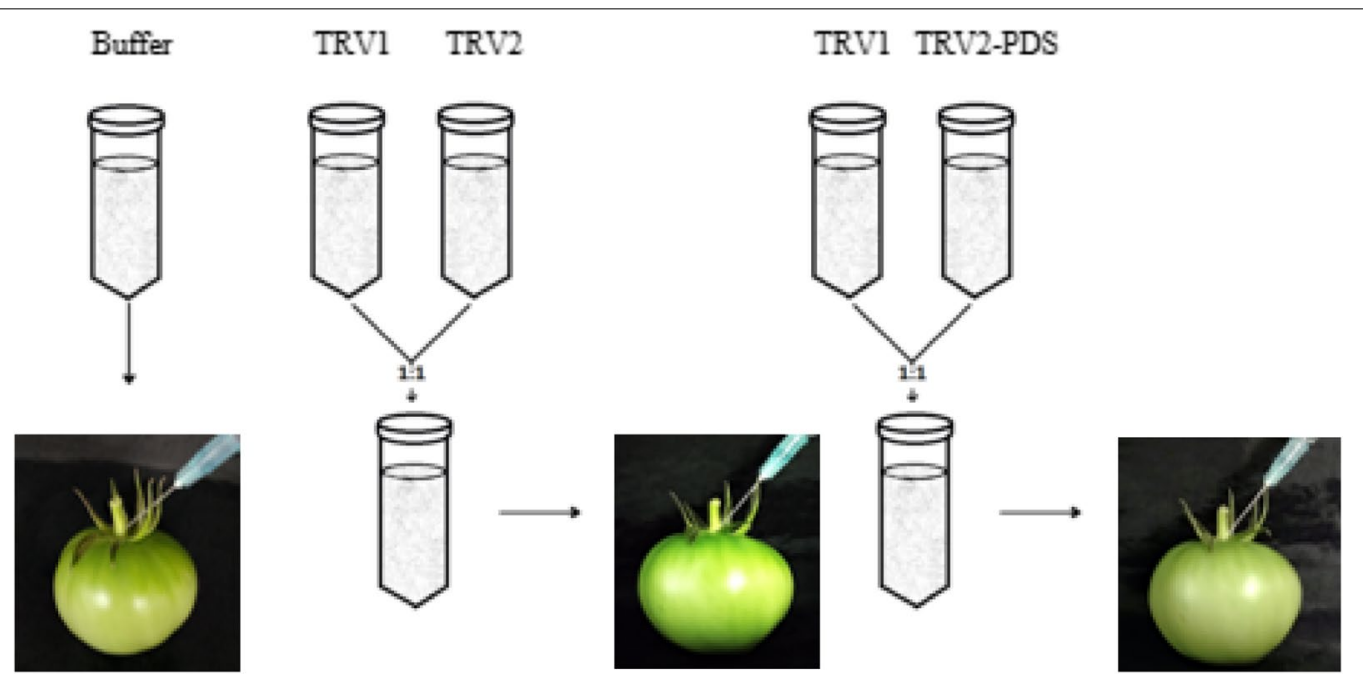

Fig. 1 Schematic of injections to the carpopodium of green mature tomato fruits using a $1 \mathrm{~mL}$ syringe 


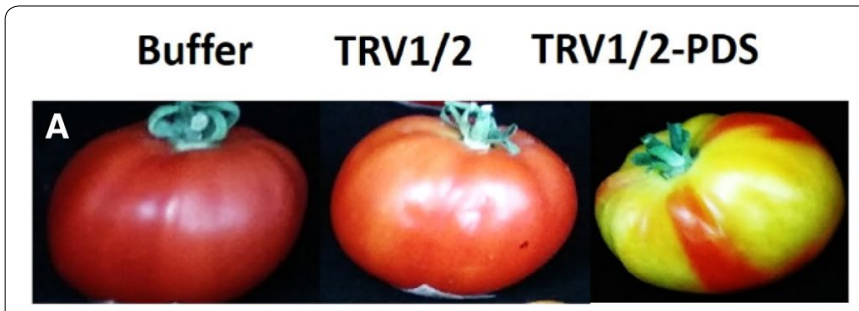

\section{Buffer}

TRV1/2

TRV1/2-PDS

C

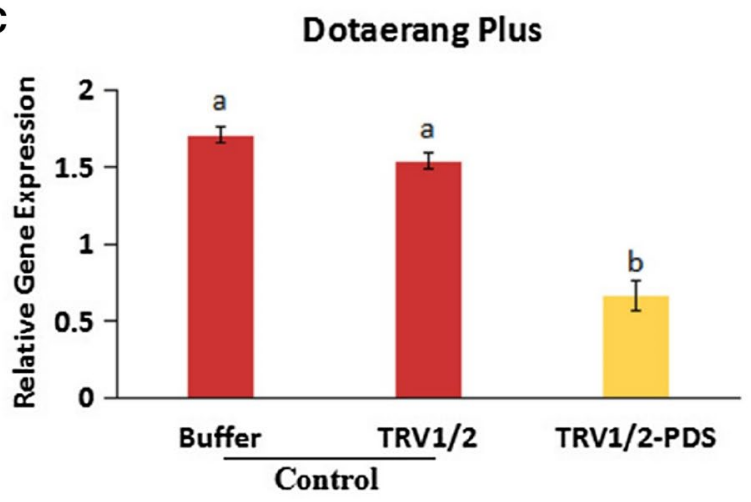

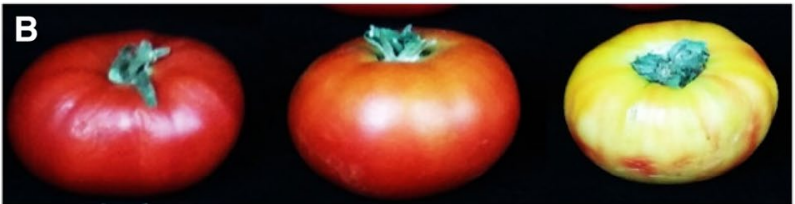

D Legend Summer

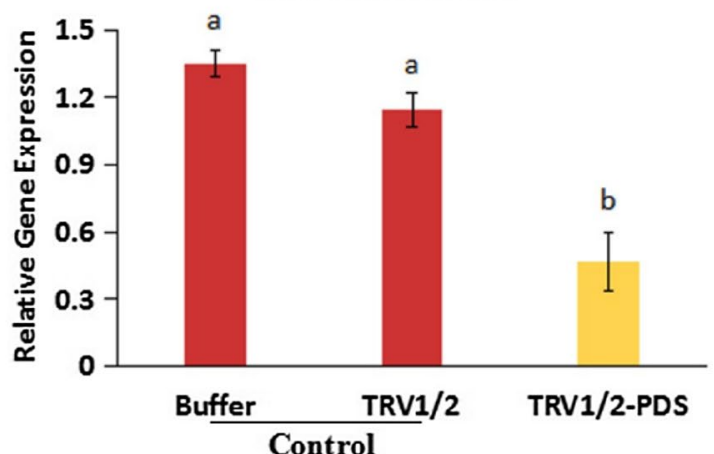

Fig. 2 Silencing of PDS in green mature fruits of two different tomato cultivars (Dotaerang Plus and Legend Summer). Different fruit phenotypes of cvs. Dotaerang Plus (A) and Legend Summer (B) injected with buffer, TRV1/2, and TRV1/2-PDS. Differences in transcript levels of the PDS gene in cvs. Dotaerang Plus (C) and Legend Summer (D) injected with buffer, TRV1/2, and TRV1/2-PDS. Data represent the mean of three biological replicates, and the bar indicates the standard deviation. Means with different letters are statistically significant $\left(\right.$ (LSDT, $\left.{ }^{*} P<0.05\right)$

virtually the entire fruit, while this was not observed in cv. Dotaerang Plus (Fig. 2A, B), indicating that there is variation in the effectiveness of silencing depending on the cultivars used. Tomatoes injected with the buffer solution or TRV1/2, which were used as controls, did not exhibit any silencing symptoms and developed the customary red color, although those tomatoes injected with the buffer solution were a deeper red compared to those injected with TRV1/2 for both cultivars (Fig. 2A, B).

\section{Expression of the PDS gene}

To clarify whether the silencing of PDS was associated with the phenotypic variation, the transcript levels of $P D S$ expressed in the pericarp of the injected fruit were determined using quantitative real time-PCR (qRT-PCR). For both cultivars, the transcript levels detected in tomatoes injected with TRV1/2-PDS (pale yellow) were significantly lower than those of the control groups (red), while the expression levels in tomatoes injected with TRV1/2 were slightly lower than those injected with the buffer (Fig. 2C, D). These results indicate that VIGS significantly inhibits PDS expression, which is consequently associated with the observed fruit phenotypes.

\section{Expression of carotenoid biosynthesis genes}

Because PDS encodes a key enzyme involved in the carotenoid biosynthesis pathway, its silencing may affect carotenoid accumulation. We investigated whether $P D S$ silencing affected carotenoid accumulation in tomatoes by measuring the expression levels of the carotenoid biosynthesis genes (ZDS, CrtR-b2, and CrtlSO), which are involved in carotenoid biosynthesis, using qRTPCR (Fig. 3A-F). Silencing of the PDS gene significantly reduced the expression levels of the biosynthesis genes compared to the control groups for both cultivars, which could lead to a reduction in the carotenoids in PDSsilenced tomatoes. This association is supported by the visual appearance of the experimental tomatoes, which appeared to have lower levels of carotenoids than the control fruit.

\section{Expression of fruit-ripening genes}

In this study, $P D S$-silenced tomatoes did not ripen, remaining pale yellow until the fruit had softened, while the control tomatoes underwent natural ripening, with softening occurring approximately 10 days earlier than in the $P D S$-silenced tomatoes. The expression levels of the known ripening genes (TAGL1, RIN, PE, LOX, FUL1, and FUL2) were analyzed for all tomatoes and found to be significantly down-regulated in the $P D S$-silenced fruits compared to the controls (Fig. 4A-L). These results suggest that $P D S$ might influence the ripening of tomatoes by regulating the expression of these genes. 

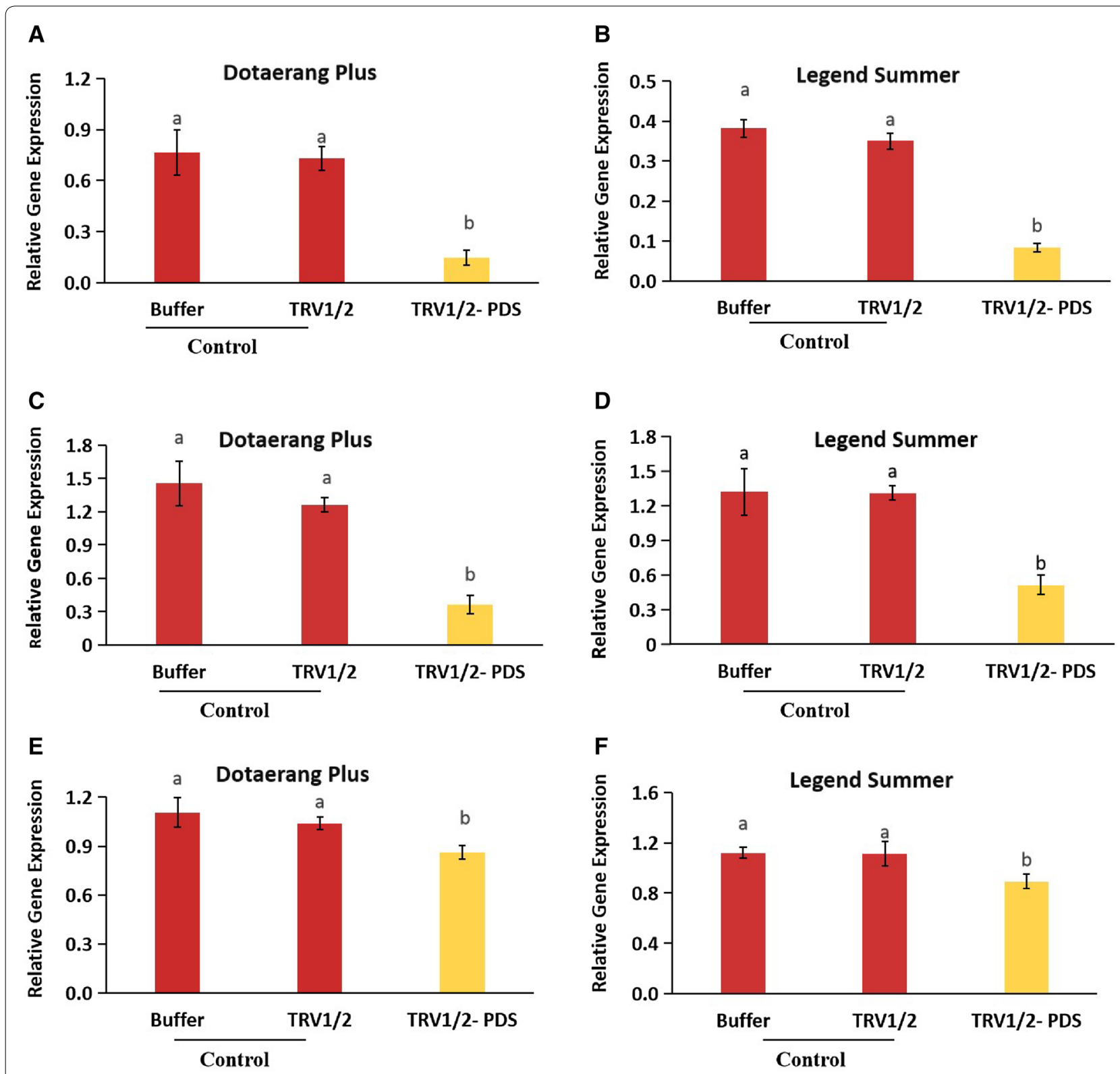

Fig. 3 Differences in transcript levels of the carotenoid biosynthesis genes, ZDS (A, B), CrtR-b2 (C, D), and CrtISO (E, F) expressed in cvs. Dotaerang Plus and Legend Summer injected with buffer, TRV1/2, and TRV1/2-PDS. Data represent the means of three biological replicates, and the bar indicates the standard deviation. Means with different letters are statistically significant (LSDT, $\left.{ }^{*} P<0.05\right)$

Expression of ethylene biosynthesis and response genes Tomatoes are climacteric, meaning their ripening is associated with the transcriptional activation of ethylene biosynthesis and response genes. We further explored the impact of reduced PDS mRNA levels on ethylene biosynthesis during the ripening process by determining the expression levels of the ethylene biosynthesis genes ( $A C O 1$ and $A C O 3$ ) and response genes (E4 and E8). Results indicated that these genes were significantly down-regulated in $P D S$-silenced fruits compared to the controls (Fig. 5A-H). These results suggest that the silencing of PDS might inhibit the transcription of these genes.

\section{Discussion}

The silencing of PDS using VIGS has been reported for a variety of plants, including tomato, pepper, and eggplant leaves, that belong to the Solanaceae family $[6,32,33]$. In these studies, PDS was used as a marker gene due to the photo-bleaching caused by its inactivation. However, 

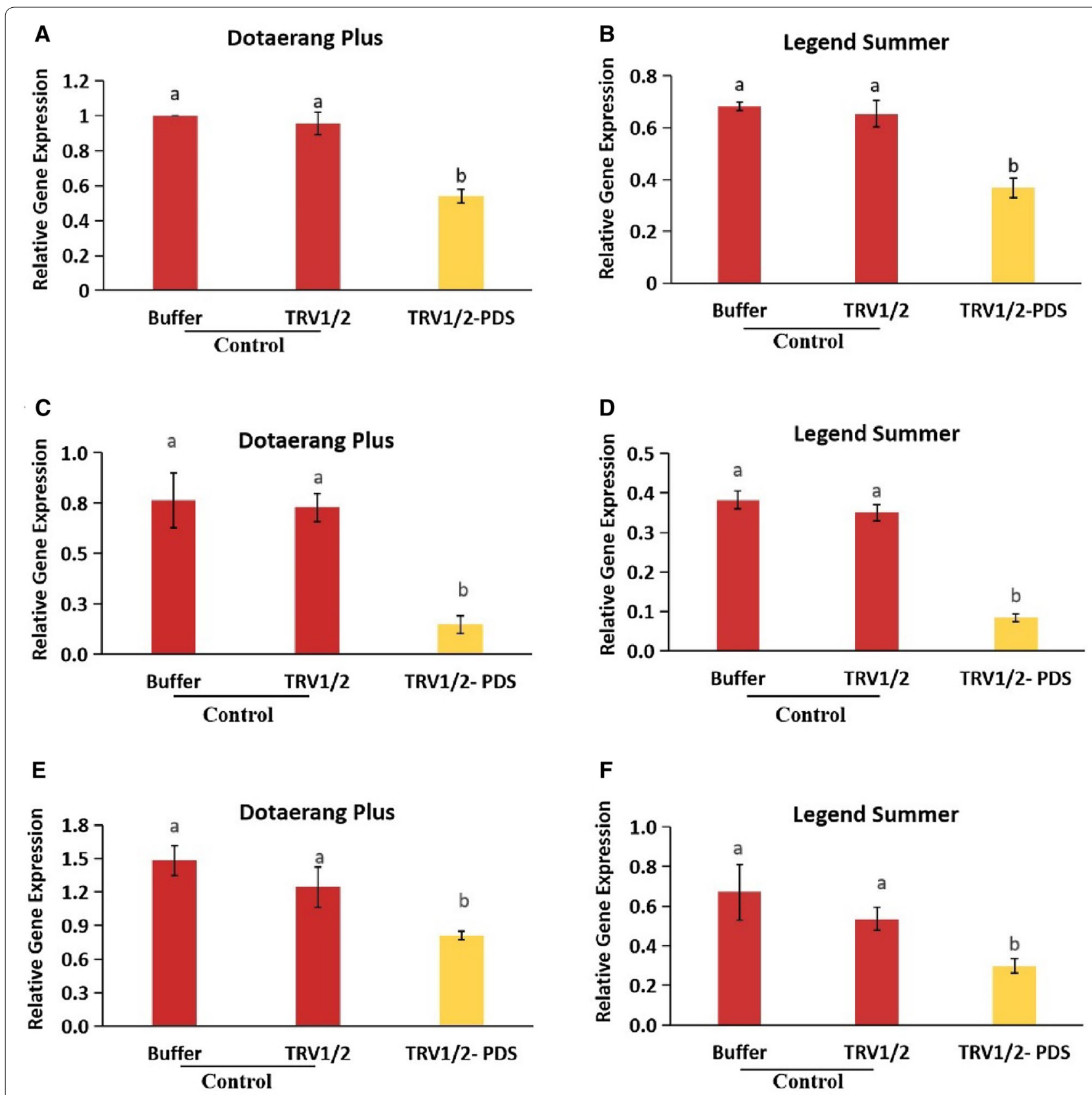

Fig. 4 Differences in transcript levels of the fruit ripening genes, FUL1 (A, B), FUL2 (C, D), LOX (E, F), RIN (G, H), PE (I, J), and TAGL1 (K, L) expressed in CVs. Dotaerang Plus and Legend Summer injected with buffer, TRV1/2, and TRV1/2-PDS. Data represent the means of three biological replicates, and the bar indicates the standard deviation. Means with different letters are statistically significant $\left(L S D T,{ }^{*} P<0.05\right)$

only a few reports have described the silencing of $P D S$ in the fruit of tomatoes $[8,9]$, and they did not examine $P D S$ gene silencing beyond photo-bleaching. Because PDS encodes an enzyme involved in the carotenoid biosynthesis pathway, it is interesting to investigate whether its silencing would inhibit the expression of carotenoid biosynthesis genes and those involved in fruit ripening and ethylene biosynthesis.
In this study, all tomato fruit of both cultivars (Legend Summer and Dotaerang Plus) injected with TRV1/2PDS exhibited a pale yellow phenotype, representing a significant difference in appearance compared to nonPDS-silenced fruits (Fig. 2A, B). Expectedly, the exploitation of the PDS gene to silence the endogenous $P D S$ gene in the tomato cultivars resulted in similar phenotypes to those reported by Orzaez et al. [8], Wang et al. [34], 

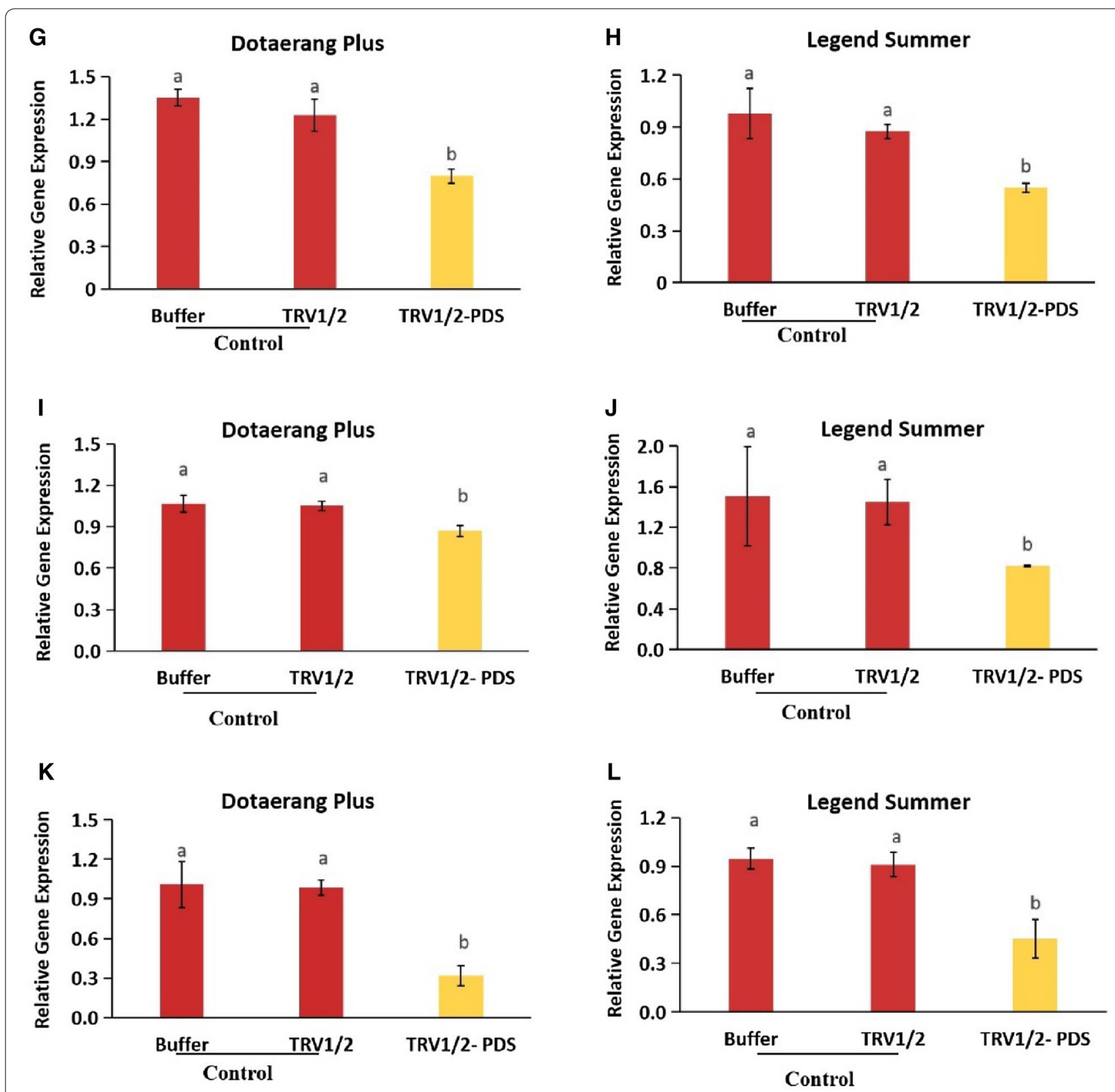

Fig. 4 continued

and Romero et al. [9], who silenced PDS in attached and detached tomatoes (cvs. Micro Tom, Maxifort, Jinfen) using the tomato PDS gene. In the control fruits, those injected with a buffer exhibited a deeper red color than those injected with TRV1/2. It is likely that "TRVI/2" itself is able to degrade PDS mRNA to some extent because the transcript levels of $P D S$ were slightly lower in the TRVI/2-treated tomatoes than in the buffer-treated fruit. The slight differences observed in the PDS-silenced areas of the two different cultivars could be due to genetic differences. A significant reduction in $P D S$ transcript levels was observed in $P D S$-silenced tomatoes compared to those of the controls, as illustrated by the resultant fruit phenotypes. Orzaez et al. [8] and Romero et al. [9] reported similar findings in their studies. These results suggest that the pepper $P D S$ gene was able to silence the endogenous $P D S$ gene in the tomato cultivars.

$\mathrm{Su}$ et al. [14] observed that carotenoid accumulation during the ripening of tomatoes is linked to the transcript levels of $C r t R-b 2$ genes. In addition, the association 


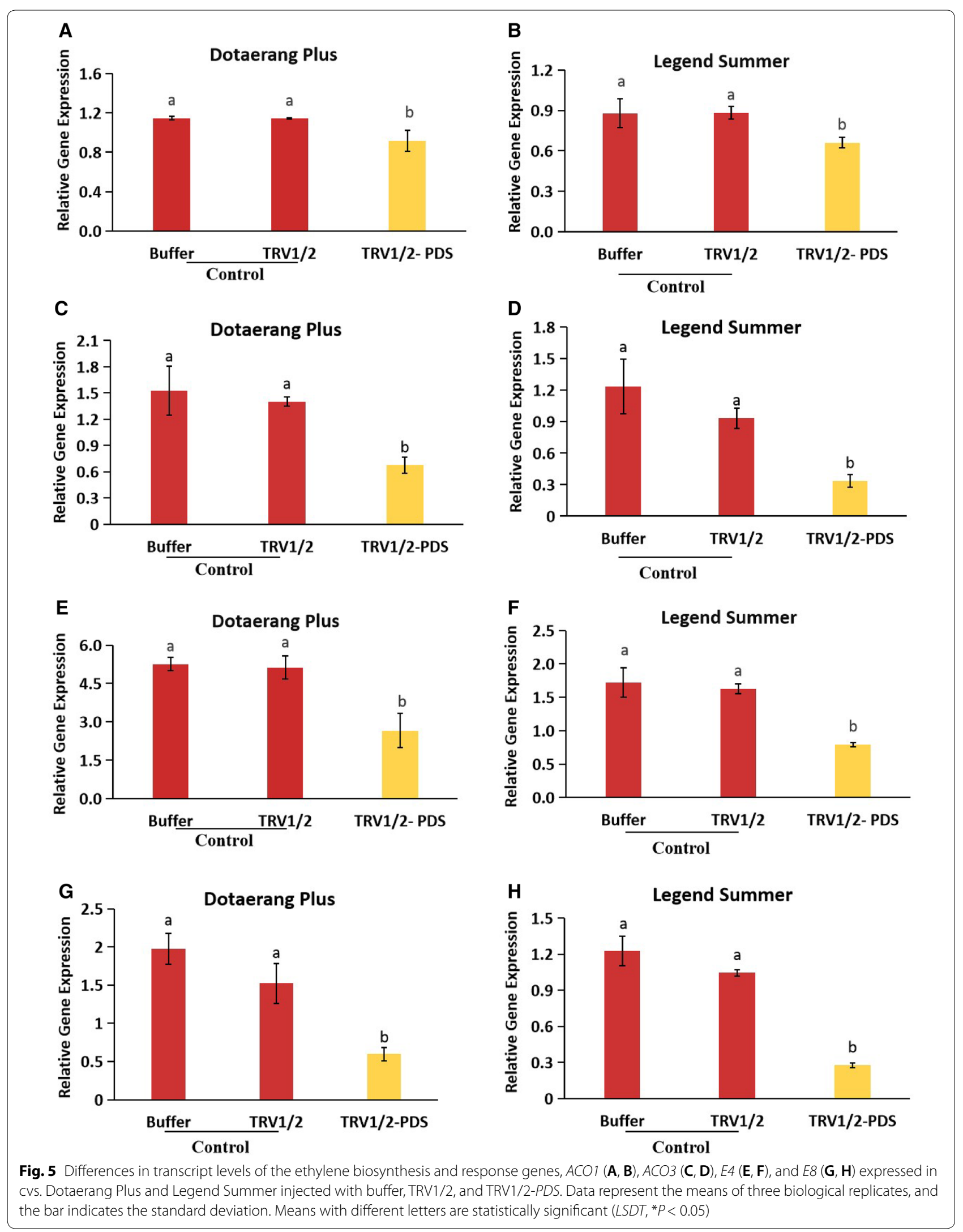


between the carotenoid accumulation and upregulation of PSY1, ZDS, CrtlSO had also been reported in tomato [11-13]. In this study, the transcript levels of the carotenoid biosynthesis genes $Z D S$, CrtR- $b 2$, and $\mathrm{CrtlSO}$ were also significantly lower in the $P D S$-silenced fruits than in the controls; these lower transcript levels were likely to prevent the accumulation of enough carotenoids to produce a red color in the fruit, as indicated by the lack of red in the $P D S$-silenced tomatoes. The lower accumulation of carotenoids resulting from the silencing of $P D S$ in the fruit of tomatoes has been reported previously, although the transcription levels of these biosynthesis genes were not specifically examined $[8,9,13]$.

The downregulation of the fruit-ripening genes TAGL1, RIN, PE, LOX, FUL1, and FUL2 was also observed in the $P D S$-silenced tomatoes but not in the controls, suggesting that $P D S$ silencing inhibited fruit ripening. Downregulation of these genes resulting in defective ripening with fruit softening has also been reported in previous research [18, 19, 35-37]. In addition, Bemer et al. [36] and Shima et al. [37] also reported that the tomato FUL1 and FUL2 genes participate in fruit ripening via their interaction with RIN. FUL1/FUL2 and RIN genes code for enzymes upstream of the ethylene signaling pathway during ripening, and suppression of these genes results in a ripening-defective phenotype with lower ethylene production [18, 37-39]. Because the downregulation of the FUL1/FUL2 and RIN genes was observed in PDSsilenced tomatoes in this study, we also expected that the downregulation of the ethylene biosynthesis and response genes $A C O 1, A C O 3, E 4$, and $E 8$ would occur, and our analysis revealed that these genes were indeed downregulated in PDS-silenced fruit. Zhang et al. [20] also suggested that the transcription levels of $P D S$ in tomato fruit were positively associated with those of other genes, such as TAGL1, FUL1/FUL2, RIN, ACO1, $A C O 3, E 4$, and $E 8$, that are involved in fruit ripening. Taken together, we conclude that the silencing of the PDS gene led to the downregulation of ethylene biosynthesis and response genes and fruit-ripening genes, leading to a ripening-defective phenotype. In some VIGS studies of fruit, $P D S$ was used as marker gene to characterize the functional role of target genes; for example, Orzaez et al. [40] identified the specific role of Delia (D) and Rosea (R) in anthocyanin accumulation in tomatoes with the combined construct TRV2:DR:PDS. However, it is relatively difficult to specifically characterize the function of a target gene due to potential side effects of PDS in terms of fruit pigmentation. Our results suggest that these effects should be taken into account when using PDS as a marker gene in the VIGS-based research of fruit.

\section{Conclusion}

We demonstrated that the pepper $P D S$ gene effectively silenced transcription of the endogenous PDS gene in the fruit of two tomato cultivars, and this silencing affected the regulation of the $Z D S$, CrtlSO, and CrtR-b2 genes, which are involved in the carotenoid biosynthesis pathway. $P D S$-silencing also appeared to affect fruit ripening, acting as a positive regulator by modulating the fruit-ripening genes TAGL1, RIN, PE, LOX, FUL1, and FUL2 and their associated ethylene biosynthesis and response genes $A C O 1, A C O 3, E 4$, and $E 8$. These results suggest that PDS silencing not only affects the carotenoid pathway but also leads to the inhibition of other genes involved in the fruit-ripening process in tomatoes. We expect that our work will aid in the better understanding of the regulatory mechanisms of $P D S$ in the fruit-ripening process.

\section{Supplementary information}

Supplementary information accompanies this paper at https://doi. org/10.1186/s13007-019-0491-z

Additional file 1: Table S1. Primers, accession numbers, and PCR conditions used for qRT-PCR analysis of the genes.

\begin{abstract}
Abbreviations
ACO1: 1-aminocyclopropane-1-carboxylate oxidase 1; ACO3: 1-aminocyclopropane-1-carboxylate oxidase 3; CrtR-b2: beta-carotene hydroxylase; CrtISO: prolycopene isomerase; E4, E8: ethylene responsive gene; FUL 1: FRUITFULL1; FUL2: FRUITFULL2; LOX: lipoxygenase; PDS: phytoene desaturase; PE: pectin esterase gene; RIN: RIPENING INHIBITOR; TAGL 1: Tomato AGAMOUS-LIKE1; TRV1: tobacco rattle virus 1; TRV2: tobacco rattle virus 2; VIGS: virus-induced gene silencing; ZDS: zeta-carotene.
\end{abstract}

\section{Acknowledgements}

This work was supported by the Korea Institute of Planning and Evaluation for Technology in Food, Agriculture, Forestry and Fisheries (IPET) through the Agri-Bio industry Technology Development Program, funded by the Ministry of Agriculture, Food and Rural Affairs (MAFRA) (Grant \#: 315002-5).

\section{Authors' contributions}

AHN designed the experiment. SYK and PPWP planted the tomatoes. JML generated the constructs. SYK prepared the inoculation solutions and agroinjected the tomato fruit. SYK and PPWP extracted total RNA. SYK and KIP designed the primers and conducted the qRT-PCR analysis. SYK statistically analyzed all of the data. AHN and SYK wrote and revised the manuscript. CKK and KBL supervised all stages of the experiments. All authors read and approved the final manuscript.

\section{Availability of data and materials}

The datasets used and/or analyzed during the current study are available from the corresponding authors on reasonable request.

Ethics approval and consent to participate

Not applicable.

\section{Consent for publication}

Not applicable.

\section{Competing interests}

The authors declare that they have no competing interests. 


\section{Author details}

${ }^{1}$ Department of Horticultural Science, Kyungpook National University, Daegu, South Korea. ${ }^{2}$ Department of Horticulture and Life Science, Yeungnam University, Gyeongsan, South Korea.

Received: 29 April 2019 Accepted: 4 September 2019 Published online: 04 October 2019

\section{References}

1. Kumagi MH, Donson J, Della-Cioppa G, Harvey D, Hanley K, Grill LK. Cytoplamic inhibition of carotenoid biosynthesis with virus-derived RNA. Proc Natl Acad Sci. 1995;92:1679-83.

2. Benedito VA, Visser PB, Angenent GC, Krens FA. The potential of virusinduced gene silencing for speeding up functional characterization of plant genes. Genet Mol Res. 2004;3:323-41.

3. Anand A, Vaghchhipawala Z, Ryu CM, Kang L, Wang K, del-Pozo O, Martin GB, Mysore KS. Identification and characterization of plant genes involved in Agrobacterium-mediated plant transformation by virus-induced gene silencing. MPMI. 2007;187:41-5.

4. Senthil-Kumar M, Hema R, Anand A, Kang L, Udayakumar M, Mysore KS. A systematic study to determine the extent of gene silencing in Nicotiana benthamiana and other Solanaceae species when heterologous gene sequences are used for virus-induced gene silencing. New Phytol. 2007;176:782-91.

5. Becker A, Lange M. VIGS genomics goes functional. Trends Plant Sci. 2009;15:1-4.

6. Liu YL, Schiff M, Dinesh-Kumar SP. Virus-induced gene silencing in tomato. Plant J. 2002;31:777-86.

7. Fu DQ, Zhu BZ, Zhu HL, Jiang WB, Luo YB. Virus-induced gene silencing in tomato fruit. Plant J. 2005;43:299-308.

8. Orzaez D, Mirabel S, Wieland WH, Granell A. Agroinjection of tomato fruits. A tool for rapid functional analysis of transgenes directly in fruit. Plant Physiol. 2006;140:3-11.

9. Romero I, Tikunov Y, Bovy A. Virus-induced gene silencing in detached tomatoes and biochemical effects of phytoene desaturase gene silencing. J Plant Physiol. 2011;168:1129-35.

10. Fraser PD, Truesdale MR, Bird CR, Schuch W, Bramley PM. Carotenoid biosynthesis during tomato fruit development. Plant Physiol. 1994;105:405-13.

11. Giuliano G, Bartley GE, Scolnik PA. Regulation of carotenoind biosynthesis during tomato development. Plant Cell. 1993;5:379-87.

12. Corona V, Aracri B, Kosturkova G, Bartley GE, Pitto L, Giorgetti L, Scolnik PA, Giuliano G. Regulation of a carotenoid biosynthesis gene promoter during plant development. Plant J. 1996;9:505-12.

13. Fantini E, Falcone G, Frusciante S, Giliberto L, Giuliano G. Dissection of tomato lycopene biosynthesis through virus-induced gene silencing. Plant Physiol. 2013;163:986-98.

14. Su L, Diretto G, Purgatto E, Danoun S, Zouine M, Li Z, Roustan JP, Bouzayen M, Giuliano G, Chervin C. Carotenoid accumulation during tomato fruit ripening is modulated by the auxin-ethylene balance. BMC Plant Biol. 2015;8:114.

15. Kim J, Park M, Jeong ES, Lee JM, Choi D. Harnessing anthocyanin-rich fruit: a visible reporter for tracing virus-induced gene silencing in pepper fruit. Plant Methods. 2017;13:3.

16. Naing AH, Song HY, Lee JM, Lim KB, Kim CK. Development of an efficient virus-induced gene silencing method in petunia using the pepper phytoene desaturase (PDS) gene. Plant Cell Tissue Organ Cult. 2019;138:507-15.

17. Vrebalov J, Ruezinsky D, Padmanabhan V, White R, Medrano D, Drake R, Schuch W, Giovannoni J. A MADS-box gene necessary for fruit ripening at the tomato ripening-inhibitor (rin) Locus. Science. 2002;296:343-6.

18. Vrebalov J, Pan IL, Arroyo AJ, McQuinn R, Chung M, Poole M, Rose J, Seymour G, Grandillo S, Giovannoni J, Irish VF. Fleshy fruit expansion and ripening are regulated by the tomato SHATTERPROOF gene, TAGL 1. Plant Cell. 2009;21:3041-62.

19. Itkin M, Seybold H, Breitel D, Rogachev I, Meir S, Aharoni A. The TOMATO AGAMOUS-LIKE 1 is a component of the fruit ripening regulatory network. Plant J. 2009;60:1081-95.

20. Zhang J, Hu Z, Yao Q, Guo X, Nguyen V, Li F, Chen J. A tomato MADS-box protein, SICMB1, regulates ethylene biosynthesis and carotenoid accumulation during fruit ripening. Sci Rep. 2018;8:3413.
21. Shima Y, Kitagawa M, Fujisawa M, Nakano T, Kato H, Kimbara J, Kasumi T, Ito Y. Tomato FRUITFULL homologues act in fruit ripening via forming MADS-box transcription factor complexes with RIN. Plant Mol Biol. 2013;82:427-38.

22. Barry CS, Blume B, Bouzayen M, Cooper W, Hamilton AJ, Grierson D. Differential expression of the 1-aminocyclopropane-1-carboxylate oxidase gene family of tomato. Plant J. 1996;9:525-35.

23. Barry CS, Llop-Tous MI, Grierson D. The regulation of 1-aminocyclopropane1-carboxylic acid synthase gene expression during the transition from system-1 to system-2 ethylene synthesis in tomatoes. Plant Physiol. 2000;123:979-86.

24. Yin W, Hu Z, Cui B, Guo X, Hu J, Zhu Z, Chen J. Suppression of the MADSbox gene SIMBP8 accelerates fruit ripening of tomato (Solanum lycopersicum). Plant Physiol Biochem. 2017;118:235-44.

25. Alexander L, Grierson D. Ethylene biosynthesis and action in tomato: a model for climacteric fruit ripening. J Exp Bot. 2002;53:2039-55.

26. Hu ZL, Chen XQ, Chen GP, Lu LJ, Donald G. The influence of co-suppressing tomato 1-aminocyclopropane-1-carboxylic acid oxidase I on the expression of fruit ripening-related and pathogenesis-related protein genes. Agric Sci China. 2007;6:406-13.

27. Olson DC, White JA, Edelman L, Harkins RN, Kende H. Differential expression of two genes for 1-aminocyclopropane-1-carboxylate synthase in tomato fruits. Proc Natl Acad Sci. 1991;88:5340-4.

28. Lincoln JE, Fischer RL. Regulation of gene expression by ethylene in wild-type and rin tomato (Lycopersicon esculentum) fruit. Plant Physiol. 1988;88:370-4.

29. Kneissl ML, Deikman J. The tomato E8 gene influences ethylene biosynthesis in fruit but not in flowers. Plant Physiol. 1996;112:537-47.

30. Kesanakurti D, Kolattukudy PE, Kirti PB. Fruit-specific overexpression of wound-induced tap1 under E8 promoter in tomato confers resistance to fungal pathogens at ripening stage. Physiol Plant. 2012;146:136-48.

31. Krasnyanski SF, Sandhu J, Domier LL, Buetow DE, Korban SS. Effect of an enhanced CaMV 35 S promoter and a fruit-specific promoter on uida gene expression in transgenic tomato plants. Vitro Cell Dev Biol Plant. 2001;37:427-33.

32. Chung E, Seong E, Kim YC, Chung EJ, Oh SK, Lee S, Park JM, Joung YH, Choi D. Method of high frequency virus-induced gene silencing in chili pepper (Capsicum annuum L. cv. Bukang). Mol Cells. 2004;17:377-80.

33. Liu HP, Fu DQ, Zhu BZ, Yan HX, Shen XY, Zuo JH, Zhu Y, Luo YB. Virusinduced gene silencing in eggplant (Solanum melongena). J Integr Plant Biol. 2012;54:422-9.

34. Wang XG, Zhu HL, Shao Y, Chen AJ, Ma YZ, Luo YB, Zhu BZ. Analysis of gene functions by a syringe infiltration method of VIGS. Russ J Plant Physiol. 2010;57:590-7.

35. Giménez E, Pineda B, Capel J, Antón MT, Atarés A, Pérez Martín F, GarcíaSogo B, Angosto T, Moreno V, Lozano R. Functional analysis of the Arlequin mutant corroborates the essential role of the Arlequin/TAGL1 gene during reproductive development of tomato. PLoS ONE. 2010;5:14427.

36. Bemer M, Karlova R, Ballester AR, Tikunov YM, Bovy AG, Wolters-Arts M, Rossetto PB, Angenent GC, de Maagd RA. The tomato FRUITFULL homologs TDR4/FUL1 and MBP7/FUL2 regulate ethylene-independent aspects of fruit ripening. Plant Cell. 2012;24:4437-51.

37. Shima Y, Fujisawa M, Kitagawa M, Nakano T, Kimbara J, Nakamura N, Shiina T, Sugiyama J, Nakamura T, Kasumi T, Ito Y. Tomato FRUITFULL homologs regulate fruit ripening via ethylene biosynthesis. Biosci Biotechnol Biochem. 2014;78:231-7.

38. Fujisawa M, Nakano T, Ito Y. Identification of potential target genes for the tomato fruit-ripening regulator $R / N$ by chromatin immunoprecipitation. BMC Plant Biol. 2011;11:26.

39. Fujisawa M, Shima Y, Nakagawa H, Kitagawa M, Kimbara J, Nakano T, Kasum T, Ito Y. Transcriptional regulation of fruit ripening by tomato FRUITFULL homologs and associated MADS box proteins. Plant Cell. 2014;26:89-101.

40. Orzaez D, Medina A, Torre S, Fernandez-Moreno JP, Rambla JL, Fernandezdel-Carmen A, Butelli E, Martin C, Granell A. A visual reporter system for VIGS in tomato fruit based on anthocyanin accumulation. Plant Physiol. 2009;150:1122-34.

\section{Publisher's Note}

Springer Nature remains neutral with regard to jurisdictional claims in published maps and institutional affiliations. 